\title{
TEORIAS E TENDÊNCIAS CONTEMPORÂNEAS DA CIÊNCIA DA INFORMAÇÃO
}

\section{CONTEMPORARY THEORIES AND TRENDS OF INFORMATION SCIENCE}

\author{
Carlos Alberto Ávila Araújo
}

UFMG

\begin{abstract}
RESUMO
Este texto apresenta os resultados de uma pesquisa que buscou mapear as abordagens e perspectivas contemporâneas de pesquisa no campo da ciência da informação. A partir de extensa pesquisa bibliográfica, chegou-se a um quadro em que se destacam treze diferentes teorias que representam novas propostas de estudo da informação. A seguir, buscou-se analisar se, no conjunto dessas teorias, seria possível perceber algum tipo de tendência ou pontos comuns. A análise evidenciou cinco aspectos do conceito de informação: sua natureza como dado ou construção; como algo individual ou coletivo; como acúmulo de dados ou interferência e apropriação; como algo técnico ou inserido na vida cotidiana; como fenômeno isolado ou inserido em uma dinâmica mais ampla. A seguir, foi utilizado como quadro analítico o esquema de Capurro, construído a partir da sistematização de três paradigmas ou formas de estudo da informação. Concluiu-se que é possível perceber que as treze teorias trabalham com o conceito de informação dentro de aspectos que podem ser identificados com o "paradigma social" identificado por Capurro.
\end{abstract}

Palavras-chave: Teorias da ciência da informação. Conceito de informação. Paradigmas da ciência da informação. Tendências contemporâneas da ciência da informação.

\section{ABSTRACT}

In this article we present the results of a research that sought to map the contemporary approaches and perspectives of research in information science. From an extensive bibliographical research, we reached a framework in which thirteen different theories stand out that represent new proposals of information study. Next, we tried to analyze if, in the set of these theories, it would be possible to perceive some type of tendency or common points. The analysis revealed five aspects of the concept of information: its nature as data or construction; as something individual or collective; such as accumulation of data or interference and appropriation; as something technical or inserted in everyday life; as an isolated phenomenon or inserted in a broader dynamic. Next, the Capurro scheme was used as an analytical framework. It was concluded that it is possible to perceive that the thirteen theories work with the concept of information within aspects that can be identified with the "social paradigm" identified by Capurro.

Keywords: Theories of information science. Concept of information. Paradigms in information science. Contemporary trends in information science. 


\section{INTRODUÇÃO}

Neste texto são apresentados os resultados de uma pesquisa que teve dois objetivos. 0 primeiro foi identificar e mapear as perspectivas, teorias e conceitos contemporâneos da ciência da informação. Para tanto, foi realizada uma extensa pesquisa bibliográfica nacional e internacional, em periódicos, livros e anais de eventos. Buscou-se separar o que eram pesquisas dentro de linhas e propostas já existentes e consolidadas no campo daquelas que representavam de fato propostas recentes e inovadoras. Também houve a preocupação de identificar perspectivas que fossem partilhadas por distintos pesquisadores, de diferentes contextos, de forma a não se concentrar em abordagens individuais, mas sim detectar movimentos teóricos coletivos, que possuem um número significativo de praticantes e seguidores, e que pudessem representar, então, uma efetiva "corrente teórica" do campo. Após esse trabalho, foram identificadas treze teorias recentes do campo. Nesse sentido, o primeiro objetivo deste texto é fazer uma apresentação panorâmica dessas treze teorias, identificando sua proposta básica de pesquisa.

O segundo objetivo da pesquisa foi questionar se seria possível encontrar uma tendência nestas treze teorias, isto é, se haveria pontos comuns entre elas que pudessem sugerir uma certa direção para a qual a ciência da informação estaria caminhando. Para a realização dessa análise, foi utilizado como quadro de referência a sistematização promovida por Capurro (2003), que identifica três "paradigmas" ou modelos de estudo da ciência da informação: o físico, o cognitivo e o social. Essa ideia, que está presente no trabalho de outros autores, tem conduzido e servido de referência para atividades de pesquisa e ensino no Brasil - o que justificou a sua escolha como parâmetro de análise.

0 artigo se estrutura, portanto, a partir destes dois objetivos. Inicialmente, são apresentadas as treze teorias encontradas. A seguir, realiza-se uma apresentação dos paradigmas de Capurro. Por fim, é realizado o confronto entre os dois quadros de forma a se verificar a possibilidade de uma tendência geral na ciência da informação, a partir da análise do conceito de informação presente nas treze teorias. 
11 | Araújo | Teorias e tendências contemporâneas da CI

\section{TEORIAS CONTEMPORÂNEAS NO CAMPO DA CIÊNCIA DA INFORMAÇÃO}

É uma tarefa difícil identificar "teorias contemporâneas" no campo da ciência da informação. Naturalmente, a revisão de literatura é o melhor caminho para identificálas. Contudo, muitas vezes, as revisões envolvem trabalhos demorados de sistematização e análise e, por isso, acabam pouco sensíveis a tendências muito recentes. Por isso, para uma identificação das tendências recentes da área, além de extensa revisão e busca na literatura, buscou-se também analisar nomes e temas de congressos da área, temáticas de edições especiais de periódicos, nomes de grupos de pesquisa e definições de áreas de concentração e linhas de pesquisa de programas de pósgraduação.

Foram consideradas como "teorias" ou "perspectivas" iniciativas muito distintas. Algumas delas são teorias de fato, outras são propostas de subáreas ou campos interdisciplinares, e outras são ações práticas que implicam desdobramentos ou consequências teóricas. Não se fez distinção entre elas no levantamento realizado.

0 resultado dessa busca levou à elaboração de uma lista muito extensa. Algumas teorias presentes nessa lista, contudo, mostraram-se muito específicas (desenvolvidas por um único autor, ou uma única instituição, por exemplo). Como forma de se ter uma lista mais sucinta, e mais representativa da área, optou-se por considerar aquelas mais significativas por sua presença em diferentes países, por seu caráter efetivamente inovador e por sua consistência conceitual (ainda que algumas vezes não explícita). Neste texto, não se tem por objetivo fazer uma apresentação extensa destas treze teorias, mas sim apresentar um panorama delas, de forma a se compor um quadro das perspectivas contemporâneas da ciência da informação que permita a identificação de uma ou mais tendências. As treze teorias são apresentadas a seguir.

\subsection{ANÁLISE DE DOMÍNIO}

A análise de domínio é uma área de pesquisa surgida, no campo da ciência da informação, a partir da publicação de um primeiro artigo de Hjorland e Albrechtsen (1995). Essa área tem como antecedente a ideia de "garantia literária" trabalhada na biblioteconomia, e se desenvolve a partir de um conceito central: "comunidades 
discursivas". Este conceito designa coletivos ou grupos sociais que possuem determinadas formas (compartilhadas) de pensar, de se expressar e de conhecer a realidade. Aplicada ao campo da ciência da informação, a análise de domínio "permite identificar as condições pelas quais o conhecimento científico se constrói e se socializa" (GUIMARÃES, 2014, p. 15) e, com isso, ver o que é importante em um dado campo, refletindo uma "construção social (um acordo intersubjetivo)" (GUIMARÃES, 2014, p. 16).

Tennis (2012) aponta que existem dois tipos de análise de domínio: a descritiva (utilizada pelos pesquisadores para desenvolverem suas pesquisas em seus respectivos campos) e a instrumental (utilizada pelos desenvolvedores de sistemas de informação e sistemas de recuperação da informação), sendo que os domínios se caracterizam por ter determinado escopo e alcance, além de um contexto próprio.

A contribuição fundamental da perspectiva da análise de domínio é a compreensão de que não é um sujeito, isolado, que tem necessidades, modos de buscar e usar a informação. "Necessidade de informação" é algo que surge coletivamente. É um grupo de pessoas que desenvolve determinados padrões de que tipo de situação ou atividade gera necessidade de informação, ou de que tipo se deve necessitar em cada contexto, e assim sucessivamente. É, enfim, um coletivo (e, no caso desta abordagem, um domínio, isto é, uma determinada área do conhecimento científico com objeto próprio, métodos próprios) que possui uma maneira de lidar com informação. Cabe ao pesquisador que desenvolve a análise de domínio detectar essas maneiras coletivas, que são públicas porque socialmente compartilhadas e vivenciadas pelos membros - isto é, porque os significados que atribuem aos processos são públicos. E ao profissional do campo da informação, cabe desenvolver serviços e sistemas de informação adaptados a esses padrões coletivos.

\subsection{ALTMETRIA}

Tradicionalmente, desde seus anos iniciais, a ciência da informação desenvolveu diversos estudos a partir da perspectiva das métricas, em uma área que recebeu diferentes designações (informetria, cientometria) e que tem como antecedente a bibliometria. No campo da ciência da informação, os estudos métricos privilegiaram a produção científica e sempre desenvolveram pesquisas buscando medir índices, Inf. Pauta, Fortaleza, CE, v. 2, n. 2, jul./dez. 2017 

principalmente a partir de citações, com objetivo de avaliação - de instituições, de produtividade de autores e para ranqueamento de revistas, entre outros. Como aponta Gouveia (2013), tais estudos apresentaram, ao longo do tempo, algumas limitações, como a lentidão (própria da comunicação científica formal), o fato de haver textos influentes que ficam à margem dos estudos, a impossibilidade de medir o impacto da produção fora do ambiente acadêmico e o uso incorreto de determinados indicadores.

Assim, no contexto da web 2.0 e do consequente desenvolvimento da chamada cientometria 2.0, o campo dos estudos métricos buscou aproveitar a oportunidade e aprimorar o estudo das dinâmicas de citação, passando a considerar o contexto e o papel dos diferentes tipos de publicações e, principalmente, as diversas maneiras como pode se expressar o impacto da produção científica - por meio de medição de acessos, comentários, links e citações em redes sociais, que compõem "indicadores de interação social" (GOUVEIA, 2016).

A origem deste campo de aplicações se deu a partir de um manifesto (PRIEM; GROTH; TARABORELLI, 2000) em que a área é definida como o estudo da comunicação científica na web social, por meio da criação e do uso de indicadores de visualização, download, citações, reutilização, compartilhamento, etiquetagem e comentários (SOUZA, 2014). Há, em seu desenvolvimento, uma clara influência da proposta de estudo da "ciência em ação" de Latour, aliada a algumas ideias básicas da web social, como a autopublicação, a colaboração, a existência de dados em larga escala, a arquitetura da participação, a ideia de rede e a lógica de abertura (open source). A importância de seu desenvolvimento é o direcionamento da pesquisa no campo da informação não só para o ambiente formal da ciência, mas o estudo da ciência imersa na vida social, na dinamicidade da vida humana. 0 "impacto", portanto, é algo socialmente construído e se realiza efetivamente em contextos concretos de uso e da experiência humana.

\subsection{CULTURA ORGANIZACIONAL}

Na ciência da informação desenvolveu-se uma tradição de pesquisas voltadas para o ambiente das organizações, sobretudo as empresariais. Inicialmente, tais estudos receberam designações como gestão de recursos informacionais e gestão da informação, passando, nos anos 1990, a vigorar a denominação gestão da informação e do conhecimento. Mais recentemente, e em sintonia com os avanços verificados na área de 
administração, começou a se destacar uma abordagem ligada à ideia de cultura organizacional. Essa noção designa o estudo do desenvolvimento dos fenômenos informacionais (necessidade, busca, compartilhamento, uso) nos níveis individual e coletivo nas organizações, buscando a articulação entre ambos por meio da identificação e análise da cultura que os permeiam (MELO; PRESSER; SANTOS, 2013). A origem deste campo na ciência da informação está vinculada ao trabalho de Davenport e Prusak em torno do estudo do aprendizado contínuo, do ambiente e do clima organizacionais enquanto proporcionadores de formas comuns de pensar e agir ou, em outros termos, padrões de valores "instituídos quanto ao tipo de comportamento, à ação e à necessidade de buscar a informação" (ALVES; DUARTE, 2014, p. 8).

Outras vezes, tal ideia desenvolve-se por meio da noção de cultura informacional, mantendo-se o mesmo significado: um conjunto de princípios, valores, crenças e ritos relacionados com a "construção, socialização, compartilhamento e uso de dados, informação e conhecimento no âmbito corporativo" (WOIDA; VALENTIM, 2006, p. 40). Trata-se, assim, do estudo da informação tendo como foco a cultura das organizações. Nessa mesma linha, uma perspectiva mais específica se desenvolveu, a de orientação informacional (MARCHAND; KETTINGER; ROLLINS, 2001), que, a partir do estudo da cultura organizacional, busca criar instrumentos para medir e otimizar a capacidade de uso da informação por parte das empresas.

A contribuição mais importante dessa abordagem, em relação ao conceito de informação, é a ideia de que, no ambiente organizacional e empresarial, o que existe não são apenas indivíduos isoladamente tomados, totalmente singulares e idiossincráticos em sua relação com os recursos informacionais, mas sim indivíduos que agem de maneira reciprocamente referenciada, que desenvolvem, em comum e nas atividades cotidianas, uma forma própria de lidar com a informação que é partilhada. Essa forma própria acaba por se constituir em algo do grupo, constitui uma "cultura". Tal contribuição, em grande medida, aproxima-se daquela da análise de domínio, embora esta esteja voltada para um domínio, isto é, uma disciplina científica, e aquela para os ambientes organizacionais. 
15 | Araújo | Teorias e tendências contemporâneas da CI

\subsection{CURADORIA DIGITAL}

A curadoria digital é mais um campo de atividade profissional e institucional do que, propriamente, uma proposta teórica. Tem se desenvolvido, portanto, mais como um conjunto de práticas e recomendações do que como campo reflexivo. Contudo, a preocupação em estabelecer alguns princípios norteadores das ações de curadoria digital (mais do que apenas um conjunto de normas e procedimentos a serem seguidos) acabou por provocar também uma importante atividade reflexiva.

Pode-se definir a curadoria digital como a prática e o estudo dos processos de seleção, preservação, manutenção, coleção e arquivamento de dados digitais, com a consequente criação de repositórios e/ou plataformas digitais participativas. Sua origem está ligada à percepção da importância da certificação de confiabilidade, da obsolescência e da evolução dos formatos (com o risco de perda pelo desenvolvimento tecnológico e pela fragilidade das mídias digitais).

Uma aplicação mais específica deste campo tem se dado, na ciência da informação, em relação à atividade científica, buscando cobrir todo o espectro de atividades, da captura à validação e arquivamento, descoberta e reuso dos dados (SAYÃO; SALES, 2012). Dessa forma, pode ser compreendida como o "gerenciamento do objeto digital e inclui atividades que abrangem todo o ciclo de vida desse objeto" (SIEBRA et al., 2015, p. 2), tendo sido desenvolvidos, para isto, alguns modelos de ciclo de vida dos dados digitais, como os de Yomaoka e Higgins. Outra definição de curadoria digital é aquela que se articula com todas as "ações de uso e preservação em relação ao meio digital que visam à reutilização de dados digitais autênticos e outros ativos digitais" (MACHADO; VIANNA, 2016, p. 2).

A contribuição mais relevante desta área é a sua preocupação com o todo, isto é, com a ligação e interdependência entre os vários aspectos, momentos e instâncias relacionados com a informação. Uma determinada ação relativa ao armazenamento impacta a coleta, a organização e as formas de acesso e disseminação, e assim sucessivamente. Há, na curadoria digital, e o próprio termo aponta para isso, uma preocupação especial, um "cuidado" (com a fragilidade dos dados, com a possibilidade de um melhor uso e reuso, etc.) que conduz a uma consideração mais sensível à globalidade dos processos e fenômenos. 


\subsection{FOLKSONOMIAS E INDEXAÇÃO SOCIAL}

Folksonomias representam um novo conceito para a organização de recursos digitais na web (CATARINO; BAPTISTA, 2009). Trata-se da consideração da indexação livre, realizada pelos próprios usuários, no trabalho dos profissionais da informação, com o objetivo de proporcionar melhor recuperação da informação - trabalho este desenvolvido em ambiente aberto e de compartilhamento; portanto, de construção conjunta.

O termo folksonomia foi criado em 2005 por Vander Val para designar a etiquetagem dos recursos da web em ambiente social, feita pelos próprios usuários. Ele surgiu com a web 2.0 e sua proposta de uma arquitetura da participação e, no campo da ciência da informação, articulada a uma dinâmica descentralizada das ações de representação da informação.

Uma designação alternativa é a expressão indexação social, que se refere à dinâmica por meio da qual os próprios usuários fazem a descrição de um mesmo recurso, resultando numa descrição intersubjetiva, realizada por meio de contratos semânticos (GUEDES; MOURA; DIAS, 2011). Também aqui, busca-se considerar tal dinâmica para a construção de linguagens de interface para organizar e recuperar conteúdos em plataformas virtuais interativas, partindo das "ações de uso social da linguagem para representar conteúdos" (GRACIOSO, 2010, p. 140).

Tal abordagem, partindo de uma postura pragmaticista, compreende que o ato de classificar (ou etiquetar, classificar, representar etc.) não é apenas um ato técnico ou profissional, passível de ser automatizado por estar sujeito a leis e padrões universais. Tal como a altmetria, a indexação social constitui uma abordagem alternativa às perspectivas tradicionais da ciência da informação. No caso da altmetria, relativa às medições de citações e produção científica; no caso da indexação social, relativa aos processos de organização da informação. De certa forma, a própria designação mais recente do campo da representação, "organização do conhecimento", já sinaliza para essa ampliação de perspectiva. Com as folksonomias, passa-se a estudar como sujeitos comuns, em suas atividades cotidianas, chegam a consensos. Representação é algo socialmente construído; e é o uso feito pelas pessoas que cria os significados dos documentos. 


\section{6 ÉTICA INTERCULTURAL DA INFORMAÇÃO}

Existem várias propostas e linhas de reflexão no âmbito das discussões sobre ética e informação - e a busca de uma possível ética informacional. Uma delas é a ética intercultural da informação, cujo foco está na "interseção entre os princípios globais e as particularidades locais" (SILVA, 2015, p. 6). Tal abordagem tem origem com a criação do International Center for Information Ethics, na Alemanha, em 2004, em torno de um questionamento fundamental: "informação para quem?", e buscou também discutir e problematizar questões informacionais debatidas no âmbito da World Summit on the Information Society, em suas distintas edições (CAPURRO, 2010).

Os eventos desta cúpula buscam promover debates entre países, governos, empresas e organizações diversas a respeito do vínculo entre informação e tecnologias digitais, verificando o impacto das tecnologias nas normas, nos princípios, nas estruturas e na própria conformação do ethos das sociedades contemporâneas. Nas edições de 2003 e de 2005, buscou-se o estabelecimento de valores comuns, tal como se procede em outras instâncias da Organização das Nações Unidas (ONU), mas também analisar como as demandas informacionais em contexto digital são entendidas dentro das diferentes tradições culturais do planeta.

É nessa linha que se desenvolveu a ética intercultural da informação, voltada, conforme Capurro (2010), para o estudo de desafios como a questão da privacidade, da propriedade intelectual, do acesso livre, do direito à expressão e da identidade digital. Em parte, tal abordagem fundamenta-se no conceito de esfera pública de Habermas, em torno da ideia de que existem atores sociais distintos, com interesses manifestos e conduzidos por meio de argumentações racionais, que se encontram e negociam numa arena pública em disputa (IULIANELLI, 2016).

0 impacto de tal abordagem no campo da ciência da informação aprofunda aquele trazido pelas reflexões de Wersig, ainda nos anos 1970, em torno da ideia de uma responsabilidade social da ciência da informação. Sua especificidade em torno da noção do "intercultural", contudo, avança na ideia de que a ética não é algo "universal", existente independente das épocas, dos lugares, das experiências concretas. É preciso discuti-la e analisá-la em cada lugar onde os fenômenos informacionais se manifestam, e a prática ética constitui, portanto, não apenas o cumprimento de determinados procedimentos profissionais, institucionais ou tecnológicos, mas também o constante 
tensionamento entre esses procedimentos e as expectativas, mentalidades e valores dos diferentes povos e saberes.

\subsection{NEODOCUMENTAÇÃO}

O movimento intelectual conhecido como neodocumentação, como o próprio nome indica, busca revitalizar um outro movimento, que se deu nas dimensões institucional, profissional, técnica e teórica - o da documentação -, originado com Paul Otlet no começo do século XX e continuado por, entre outros, Suzanne Briet na França, López Yepes na Espanha e Bradford no mundo anglo-saxão.

A proposta da neodocumentação, desenvolvida no campo da ciência da informação por autores como Rayward e Frohmann, propõe a substituição do termo "informação", tal como usado na ciência da informação, para o termo "documento". Tal ideia é entendida não como um desvio, mas como um reenvio - informação é entendida, para tais autores, como o efeito ou derivação dos documentos (GONZÁLEZ DE GÓMEZ, 2011). Para os autores vinculados a essa abordagem, ao abandonar o documento e centrar-se na informação, entendida como o "conteúdo objetivo" dos documentos, a ciência da informação divorciou-se das práticas sociais, políticas, econômicas e culturais nas quais a informação é produzida. 0 "documento" traz as marcas de seu contexto, de quem o produziu, do suporte em que está inscrito, de suas dimensões e tamanho, de seus aspectos estéticos, entre outros. Ao se desconsiderar tudo isso, buscando apenas os "dados" ali contidos, a ciência da informação perdeu dimensões importantíssimas dos fenômenos informacionais. A neodocumentação busca, assim, uma certa reconciliação entre o estudo da informação e a vida social. Há aqui, como na altmetria e na folksonomia, uma clara dimensão pragmaticista, por meio, neste caso, da influência de Wittgenstein, para quem o significado só existe e emerge a partir do uso feito pelos sujeitos em suas ações concretas. Há, pois, um reencontro com as dimensões contextuais às quais o documento encontra-se vinculado e seu uso. Um documento possui as "marcas" de sua origem, e é a noção de "materialidade" que permite identificar essa ligação. 


\subsection{HUMANIDADES DIGITAIS}

Humanidades digitais representa um amplo movimento, realizado em vários países em anos recentes, e que tem produzido impactos diferenciados nas disciplinas científicas. Em linhas gerais, ela tem por objetivo romper com a separação verificada, nas últimas décadas, entre as tecnologias digitais e as humanidades, buscando, justamente, conciliar os métodos das ciências humanas e sociais com as características, potencialidades e procedimentos do mundo digital. Recentemente, tem tido presença no campo da ciência da informação (PIMENTA, 2016).

Na ciência da informação, o principal diálogo com as humanidades digitais tem se dado no campo das discussões sobre preservação de patrimônios culturais nas sociedades contemporâneas, a promoção do acesso universal de forma democrática e o embasamento crítico para a elaboração de políticas públicas de desenvolvimento tecnológico (ALMEIDA; DAMIAN, 2015). Consiste, pois, no planejamento, proposição e perspectivas de uso das tecnologias digitais a partir das preocupações típicas das humanidades.

Essa abordagem compreende o ciberespaço como um espaço de mediação de um conjunto de atividades e construção coletiva de repertórios culturais. Ao fazer isso, permite e potencializa uma compreensão das tecnologias não apenas nelas mesmas, em seus elementos componentes, recursos e operacionalizações, mas como dispositivos sociotécnicos, isto é, elementos articulados aos demais fazeres humanos. Por isso, é fundamental compreender seu impacto e as distintas possibilidades de seu uso.

\subsection{ARQUEOLOGIA DA SOCIEDADE DA INFORMAÇÃO}

A temática da "sociedade da informação" tornou-se uma constante nas décadas de 1960 e 1970 e consistiu, em certa medida, a fundamentação para o surgimento e o desenvolvimento da ciência da informação. Os autores que promoviam a noção buscaram, com seu uso, destacar um novo momento na história da humanidade, em que a informação (ou o conhecimento, ou a inovação, as ideias) desempenharia um papel fundamental como modo de produção, tornando-se mais importante ou central do que a indústria e a agricultura. Tal ideia legitimou a construção da ciência da informação, uma ciência voltada para o estudo dessa nova era e desse recurso tão importante, bem como 
a elaboração de distintos projetos de "entrada" na sociedade da informação em distintos países, inclusive no Brasil.

Alguns pesquisadores, contudo, começaram a levantar questionamentos sobre o caráter de "novidade" desse fenômeno, bem como do discurso promocional envolvido em torno da noção. Tais autores desenvolveram uma verdadeira arqueologia da ideia de sociedade da informação. Um destes autores, Burke (2012), buscou demonstrar como, ao longo de sua história, a humanidade desenvolveu distintas formas de coletar, analisar, disseminar e usar a informação, relativizando parte do discurso em torno da sociedade da informação, que apresentava muitos processos como originais ou inéditos na história.

Outro autor, Mattelart (2002), realizou um trabalho de estudo da vinculação entre o discurso eufórico da sociedade da informação e processos e projetos de dominação na geopolítica planetária, de consolidação de hegemonias, por meio do conceito de ideologia. Nessa mesma linha, Day (2001) buscou analisar criticamente como se desenvolveu e que interesses se articularam no desenvolvimento da noção de sociedade da informação.

Tal abordagem intentou desmistificar o caráter deslumbrado do discurso da sociedade da informação, de inevitabilidade e universalidade, por meio do estudo da complexidade de fenômenos e desdobramentos em diferentes contextos, conforme a geopolítica internacional

\subsection{PRÁTICAS INFORMACIONAIS}

Uma das subáreas que sempre se desenvolveu com relativa autonomia na ciência da informação foi a dos estudos de usuários. Originários dos estudos de usuários de bibliotecas, tal perspectiva desenvolveu-se, inicialmente, como estudos de uso da informação (estabelecimento de perfis de públicos, levantamento de padrões de busca e uso para diagnóstico e avaliação de sistemas de informação), passando, a partir dos anos 1980, a ter como central a perspectiva do comportamento informacional. Diversos modelos foram elaborados nesta perspectiva. Em meados da década de 1990, a partir da iniciativa de um grupo de finlandeses (TUOMINEN; TALJA; SAVOLAINEN, 2002), uma outra abordagem começou a ser desenvolvida: os estudos em práticas informacionais. 
Há, nesta abordagem, uma fundamentação na etnometodologia, a partir do conceito de "prática" em Garfinkel, isto é, o movimento por meio do qual os indivíduos agem no mundo, conformados pela cultura, e, ao mesmo tempo, constituem essa cultura que os influencia e a realidade em que atuam. Outra fundamentação vem de Bourdieu e seu conceito de habitus, o conjunto de predisposições que são interiorizadas pelos indivíduos no decorrer de suas ações e posicionamentos nos distintos campos de atividade humana. Inicialmente, tal abordagem focava-se em estudos de usuários na vida cotidiana, em oposição aos estudos tradicionais focados no ambiente científico, governamental e empresarial (SAVOLAINEN, 1995), mas depois passaram a se constituir numa perspectiva para todos os tipos de realidade empírica.

Estudos como o de McKenzie (2003), nessa linha, têm evidenciado a existência de uma comunidade de praticantes: a busca e a recuperação de informação são dimensões das práticas sociais que fazem parte das rotinas, sejam elas da vida cotidiana ou do mundo do trabalho. A pesquisadora também argumenta que as práticas informacionais são singulares e situacionais, não sendo regidas por leis e bastante sujeitas ao acaso.

Entre as contribuições dessa linha de investigação está a ideia de que não existe um mundo exterior, "lá fora”, independente dos sujeitos e das suas ações. São os sujeitos que, em suas ações, criam e atualizam as regras e normas sociais. Além disso, tais estudos, na crítica à proposta do comportamento informacional, avançaram na compreensão da informação não como o preenchimento de uma lacuna cognitiva, nem um processo exclusivamente vivido da perspectiva individual. Os processos envolvidos com o uso da informação envolvem imaginação, apropriação, questionamentos, tensionamentos, e tais processos são vividos a partir de categorias construídas socialmente. Os sujeitos agem diante de outros, em ações correferenciadas, e tais ações se dão em ligação com os contextos concretos em que acontecem. Em certa medida, verifica-se algo parecido com o que foi desenvolvido na análise de domínio e nos estudos em cultura organizacional, mas aqui voltados para os mais distintos ambientes e circunstâncias.

\subsection{REGIMES DE INFORMAÇÃO}

Uma das perspectivas mais disseminadas no cenário contemporâneo da ciência da informação é a abordagem conhecida como regimes de informação. Tal abordagem 
baseia-se na noção de "modo de produção" de Marx, aplicada ao campo da ciência da informação. Um regime de informação designa, assim, um modo informacional dominante em uma sociedade, isto é, quem são os sujeitos, as organizações, as regras, as autoridades, os recursos e as hierarquias que conformam um determinado regime, isto é, determinadas condições de existência de discursos e enunciações (GONZÁLEZ DE GÓMEZ, 2012).

Tal ideia vem sendo desenvolvida por, entre outros, Braman (2004) por meio da noção de cadeias de produção da informação na análise da circulação da informação em diferentes países e a formulação de políticas públicas no setor. Outro fundamento para a abordagem vem do conceito de "dispositivo" em Foucault, autor resgatado por Frohmann (2008) para a análise de por que determinados documentos existem e ganham "força e massa", inscrevendo-se em institucionalidades e gerando determinados efeitos e fatos na vida social.

Os autores ligados a essa linha de estudos analisaram, principalmente, as políticas de informação, não apenas em seus aspectos normativos ou operacionais, mas em sua imersão e inter-relação com as várias dimensões da vida humana - a social, a cultural, a econômica, a política, a regulatória, entre outras (FROHMANN, 1995). Conhecer a informação por meio do conceito de regimes de informação significa que não se deve estudá-la nela mesma, em seus componentes e elementos internos, mas sim compreendê-la como produto da interação entre os vários fatores que a tornam possível e que condicionam a sua existência.

\subsection{MEMÓRIA}

Memória é um tema ou conceito que sempre esteve presente, de alguma forma, no campo da ciência da informação. Nas últimas duas décadas, contudo, tem tido maior destaque, passando a designar áreas de investigação, linhas de pesquisa em programas de pós-graduação e grupos de trabalho em associações científicas. Esse movimento deuse também com o progressivo abandono de uma perspectiva tecnicista da ideia de memória (ligada a processamento e recuperação da informação, a capacidades e potencialidades de computadores e redes) e sua problematização a partir de contribuições dos campos da história e da antropologia, entre outros (MURGUIA, 2010). 
Nesse sentido, os fundamentos dessa nova aproximação entre os conceitos de informação e memória se encontram nos trabalhos de Nora (1993), que entende a memória como fenômeno vivido individualmente, mas articulado a suportes externos materiais (o conhecimento registrado), e Halbwachs (2003), para quem a memória individual está situada na encruzilhada das redes de solidariedade diversas nas quais todos estamos envolvidos.

De uma perspectiva individualista, ligada a uma capacidade humana, o entendimento da memória passou a ser visto dentro de um quadro da sua construção social, do seu papel na constituição da cultura e da própria realidade. Mais ainda, a maneira como os distintos indivíduos e grupos participam desse processo conduziu a uma compreensão da memória como um "campo de batalha", no qual os atores lutam pelo estabelecimento dos critérios a partir dos quais será decidido o que será, coletivamente, lembrado e esquecido, valorizado e desprezado. Estudos recentes têm se debruçado sobre as condições de produção (e o direito de participação nesta produção), de circulação (e a importância da pluralidade e da diversidade nesse processo) e de acesso (garantia de que seja o mais democrático possível) da informação na constituição da memória. Uma referência nessa linha é García Gutiérrez (2008) com sua proposta de criação de dois tipos de dispositivos: o operador complexo e o operador transcultural.

Aqui, também, vê-se uma crítica à ideia de informação como o preenchimento de uma lacuna dos indivíduos. Informação é entendida como o processo a partir do qual indivíduos valorizam determinados registros e, nesse processo, participam do processo de construção da memória, portanto da cultura e do real. Os serviços, produtos e sistemas de informação são estudados como atores na conformação de determinados quadros de sentido, modos de apreensão, interferências na valorização de determinadas fontes, documentos ou registros.

\subsection{APROXIMAÇÕES COM ARQUIVOLOGIA, BIBLIOTECONOMIA E MUSEOLOGIA}

Uma tendência que vem sendo desenvolvida na ciência da informação em anos recentes diz respeito ao argumento de que ela deveria fortalecer seu diálogo com as áreas de arquivologia, de biblioteconomia e de museologia. Não se trata, como as outras, de uma teoria ou um conjunto de ações e práticas, nem mesmo de um movimento intelectual unificado. Encontram-se aqui distintas iniciativas, sobretudo de âmbito 
institucional. Uma delas é a de Bates (2012), que aproxima a ciência da informação dos conceitos de conhecimento, memória e patrimônio, a partir de uma ligação com, respectivamente, biblioteconomia, arquivologia e museologia. Silva e Ribeiro (2002) defendem, numa linha diferente, um outro tipo de aproximação a partir das categorias de "custodial" e "pós-custodial". Vivarelli (2015) propõe que arquivos, bibliotecas e museus devem ser parceiros por terem as mesmas finalidades em relação ao seu uso público e papel de promotores da cultura e espaço de construção da identidade.

Conforme Araújo (2014), é possível perceber uma sintonia entre as perspectivas teóricas mais recentes nas três áreas. A nova biblioteconomia, o conceito de mediação bibliotecária e a competência informacional na biblioteconomia; os conceitos de archivalia e archivalization, a arquivística integrada e a arquivística pós-moderna na arquivologia; a ideia do museal, a nova museologia e a museologia crítica na museologia possuem, todas, uma ideia comum: o estudo das maneiras pelas quais uma sociedade lida com o conhecimento que ela própria produz. Arquivos, bibliotecas e museus, seus fazeres e seus profissionais, são entendidos como mediações, interferências específicas realizadas no âmbito da dinâmica informacional mais ampla de uma sociedade.

Aproximar a ciência da informação destas três áreas é, assim, tentar compreender como uma cultura é produzida, reproduzida e modificada por meio das interferências destas instituições; é analisar a dinâmica dessas várias interferências, promovidas por atores institucionais ou não, nos distintos processos de criação, seleção, circulação e apropriação dos registros de conhecimento.

\section{A DISCUSSÃO SOBRE OS PARADIGMAS}

As treze teorias apresentadas acima vinculam-se a tradições de pesquisa muito distintas (os estudos em organização da informação, pesquisas métricas, estudos de usuários, gestão da informação, comunicação científica, entre outros). Elas também evidenciam o caráter dinâmico e plural da ciência da informação, que se dedica ao estudo de diferentes realidades empíricas (os fluxos de informação no planeta; os contextos organizacionais; a organização de documentos em bibliotecas, arquivos, bases de dados; a apropriação da informação no cotidiano; entre muitas outras) e, para tanto, aciona conceitos e métodos também distintos. 
Seria possível, contudo, encontrar pontos comuns entre elas? Haveria uma ou mais tendências gerais verificáveis na ciência da informação? Para desenvolver essa análise, foi utilizado como quadro de referência a proposta de "paradigmas" da ciência da informação apresentada por Capurro.

Em 2003, durante o Enancib, o Encontro Nacional de Pesquisa em Ciência da Informação, houve uma conferência de abertura promovida por Rafael Capurro, então professor da Universidade de Stuttgart. Nela, ele apresentou aqueles que seriam os três principais modelos de estudo da informação desenvolvidos pela ciência da informação (CAPURRO, 2003). Essa ideia, seja pela sua importância institucional (foi a conferência magna do principal evento da área no país), pela sua qualidade intelectual (a fundamentação consistente da argumentação) ou pela sua clareza didática e esquemática, tornou-se uma referência importante para os pesquisadores brasileiros. Gerou-se, a partir dali, certo consenso sobre o que é a área, sobre sua evolução, que passou a refletir-se na produção científica e, também, no ensino (trata-se de um artigo presente em programas de disciplinas de fundamentos da ciência da informação em cursos de graduação e pós-graduação e em editais de seleção para mestrados em ciência da informação).

Na verdade, a sistematização proposta por Capurro não era exatamente nova ou totalmente original. Antes e depois dele, outros apresentaram sistematizações razoavelmente semelhantes. 0 próprio Capurro apresentou uma em 1991, e depois disso autores de proveniências institucionais distintas, como Rendón Rojas (México), Saracevic (Estados Unidos), Ørom (Dinamarca), Fernández Molina e Moya Anegón (Espanha), Silva e Ribeiro (Portugal) e Salaün e Arsenault (Canadá), apresentaram outras sistematizações (ARAÚJO, 2014). Todos estes autores, embora usando termos diferentes, identificaram três grandes conceitos ou modelos de estudo da informação.

$\mathrm{Na}$ obra de todos eles, ressalta-se a ideia de que houve uma primeira forma de estudo da informação ("física", como fenômeno "objetivo", como "sinal", como algo no nível "sintático"), em que ela era entendida como algo existente em si mesmo, independente dos sujeitos e dos contextos, como um "dado", dotado de propriedades e características passíveis de serem medidos e explicados a partir da formulação de leis. Em suas argumentações sobre esse primeiro modelo, os autores vinculam "informação" a noções como sinal, emissor, receptor, transporte, transferência, sistema, recuperação, probabilidade, precisão, revocação, mensagem. Esse modelo, conforme os autores, teria 
"origem" naquele que é o evento também identificado, muitas vezes, como originário do próprio campo: as Conferences on Training Science Information Specialists, ocorridas no Georgia Institute of Technology, em 1961 e 1962. Seus fundamentos teóricos básicos estão expressos no artigo As We May Thing, de Vannevar Bush, publicado em 1945; no livro The mathematical theory of communication, de Shannon e Weaver, publicado em 1949; e no artigo Information Science: what is it?, de Borko, publicado em 1968. Quadros de referência fundamentais em sua construção foram as teorias do comportamentalismo e da teoria sistêmica, hegemônicos no período da gestação do projeto da ciência da informação.

Também em todos os autores mencionados acima há a ideia de que surgiu uma segunda maneira de se estudar a informação (como algo "cognitivo", "semântico", "subjetivo"), em que passou a se considerar a articulação entre os dados (os elementos presentes da realidade independente dos sujeitos) e o conhecimento (aquilo que os indivíduos sabem ou conhecem), sendo a informação a medida da alteração deste estado de conhecimento, ou, em outros termos, o produto da interação entre os dados e o conhecimento, no âmbito do indivíduo. Ao apresentarem essa perspectiva de estudos, os autores aproximam o conceito de "informação" ao de dado, conhecimento, processamento, indivíduo, pessoa, lacuna, preenchimento, modificação, alteração, significado. Esse modelo tem como marco de referência a The Copenhagen Conference Theory and Application of Information Research, ocorrida em 1977, e se expressou teoricamente em quatro artigos sobre Foundations of Information Science, publicados por Brookes no início dos anos 1980, nos quais o autor apresenta a sua "equação fundamental" da ciência da informação - e no qual a informação é compreendida como a medida da alteração da estrutura de conhecimento de um indivíduo. A inspiração filosófica dessa abordagem é a teoria do conhecimento objetivo de Popper.

Mais uma vez, em todos os autores mencionados há a ideia de um terceiro modelo, que em alguns aparece como uma tendência ainda em construção, em outros já se encontra mais estabelecida. Termos como "pragmática", "intersubjetivo", “sociocultural” são usados para descrevê-la, apontando que informação é algo da ordem não apenas do objetivo ou do subjetivo, mas também do coletivo, de uma construção social. Nessas descrições, "informação" aparece ligada a termos como documento, saberes, ação, contexto, cultura, memória, coletivo, sociedade, histórico. 0 marco de referência da construção dessa perspectiva é o I CoLIS - International Conference on Inf. Pauta, Fortaleza, CE, v. 2, n. 2, jul./dez. 2017 
Conceptions of Library and Information Science, que ocorreu na Finlândia, em 1991, e teria marcado uma "virada sociológica" na ciência da informação (CRONIN, 2008). Antecedentes desse modelo são, no campo da ciência da informação, a epistemologia social proposta por Shera nos anos 1960 e, de fora da área, as teorias da construção social da realidade de Berger e Luckmann e o movimento da viragem linguística, promovido por pragmaticistas como Wittgenstein.

Essas sistematizações da ciência da informação a partir de três modelos ou formas de estudo podem ser utilizadas como parâmetro para a caracterização das teorias e perspectivas que compõem a ciência da informação. Assim, decidiu-se realizar, como trabalho de pesquisa, a busca, nas treze teorias identificas, de como se manifesta(m) o(s) conceito(s) de informação a partir do quadro de referência dos três modelos.

\section{O CONCEITO DE INFORMAÇÃO NAS TENDÊNCIAS CONTEMPORÂNEAS}

Após a breve apresentação das treze teorias e dos três paradigmas, pode-se perceber que existem certas tensões em relação à maneira como a informação é compreendida. Algumas dessas teorias são construídas justamente na oposição a outras teorias ou modelos, já consolidados no campo, apresentando-se como formas alternativas de compreensão dos fenômenos informacionais.

A análise dos conceitos mobilizados pelas treze teorias, dos temas propostos e formas de estudo, permite evidenciar pelo menos cinco dimensões dos fenômenos informacionais: sua natureza como dado ou construção; como algo individual ou coletivo; como acúmulo de dados ou interferência e apropriação; como algo técnico ou inserido na vida cotidiana; como fenômeno isolado ou inserido em um dinâmica mais ampla. Cada um deles é analisado a seguir:

a) Em alguns casos, a informação é entendida como algo objetivo, físico, fixo, pronto, um "dado" da realidade. Em outros, ela é vista como algo construído, um fenômeno dependente de um sujeito, relacionado a dinâmicas de significação e valoração. Nas treze teorias analisadas, predomina o segundo entendimento, o que as aproxima do paradigma social. 
b) Em certos casos, a informação é vista como algo individual, ligado a pessoas tomadas como entes isolados (e somente em sua dimensão de seres cognoscentes), enquanto em outras é tomada como fenômeno cultural, de natureza intersubjetiva, isto é, como construção por meio da ação reciprocamente referenciada dos atores sociais. Nas treze teorias analisadas, também se destaca a segunda ideia - e que está ligada ao paradigma social.

c) Além disso, a relação das pessoas com os registros de conhecimento é vista, em alguns casos, como um acúmulo, um somatório de conhecimentos, envolvido com o processamento da informação. Em outros casos, analisa-se a interferência dos sujeitos, os processos de acomodação e assimilação que se instauram em sua relação com o real, o uso da imaginação, os processos de apropriação. Também aqui é possível perceber que a segunda explicação, ligada ao paradigma social, predomina nas teorias analisadas.

d) Ainda, em alguns casos, a informação é estudada como algo técnico, formal, inscrito na dinâmica da ciência, do ambiente empresarial ou laboral, tomados isoladamente, sendo o processamento da informação passível de ser automatizado, estando os fenômenos informacionais sujeitos a leis. Em outros casos, a informação é vista como algo presente na vida cotidiana, ligado à ação dos sujeitos, fenômeno singular, portanto da ordem da contingência, e com caráter pragmático. Mais uma vez, percebe-se o predomínio do segundo entendimento, também este ligado ao paradigma social.

e) Por fim, a informação é vista, em certos estudos, como um sistema isolado, analisada em seus elementos internos, suas partes constitutivas, sem referência ao contexto em que se inscreve. Em outras, como um fenômeno que não existe em si mesmo, mas sim um aspecto de relações mais amplas, inscrito numa dinâmica maior (numa lógica, portanto, de maior complexidade em busca da globalidade do fenômeno). É essa segunda forma de compreensão que predomina nas treze teorias, e ela também está vinculada ao paradigma social.

Analisando, pois, as treze perspectivas contemporâneas, é possível identificar claramente aspectos dos modelos físico e cognitivo que são questionados, isto é, construções conceituais que evidenciam que o poder explicativo dos modelos físico e Inf. Pauta, Fortaleza, CE, v. 2, n. 2, jul./dez. 2017 
cognitivo mostra-se limitado. A informação tem claramente uma dimensão objetiva, que pode ser identificada, e envolve sim um transporte, uma transferência de algo de um sujeito para outro (e, portanto, informação tem sim a ver com sinal, emissor, receptor, sistema, recuperação). A informação envolve também uma alteração do estado cognitivo de uma pessoa, a transformação de dados em conhecimento (e então informação tem relação com conceitos como dado, conhecimento, lacuna, pessoa, preenchimento, necessidade, busca, uso).

Embora as teorias atuais enxerguem esses elementos, elas não os priorizam. Pelo contrário, constroem-se na crítica à limitação que consiste em estudar apenas essas dimensões. Nesse sentido, as treze teorias demonstram que informação também é algo mais amplo e complexo do que o que é expresso em suas dimensões física e cognitiva ela existe em dimensões que estão além da dimensão propriamente operacional e mecânica. Trata-se, como vem sendo apontado e de fato exercido pelas treze tendências apresentadas, de um processo no qual as identidades dos sujeitos são construídas, e a cultura é constituída a partir de ações de criação e apropriação dos registros de conhecimento (documentos) pelos sujeitos agindo de forma reciprocamente referenciada na construção dos saberes. Informação se relaciona, portanto, com conceitos como cultura, memória, apropriação, mediação, documento, saberes. As treze teorias atuais demonstram que há uma clara tendência intelectual no campo da ciência da informação, sem que as dimensões física e cognitiva, priorizadas em outras maneiras de se pensar a informação (os dois primeiros paradigmas), tenham deixado de existir.

\section{CONSIDERAÇÕES FINAIS}

Em um texto muito conhecido sobre o conceito de informação, Capurro e Hjorland (2007) perguntam que diferença faz se usamos um ou outro conceito de informação. Sabemos que os conceitos são criações do pesquisador, eles não existem “ali, na realidade". O que temos diante de nós são fatos, fenômenos como, por exemplo, pessoas indo à biblioteca, políticas de preservação de documentos sendo formuladas, processos de digitalização ocorrendo, comunidades interagindo por redes sociais, públicos visitando museus, audiências acompanhando a televisão, aulas ocorrendo por videoconferência, pessoas acessando motores de busca etc. O empírico está lá - o que muda é nossa forma de compreendê-lo. Cada um desses processos pode ser analisado 
em termos de transferência de dados, de alteração de estados de conhecimento ou de construção coletiva de saberes e identidades.

A análise das treze teorias realizada neste texto demonstrou que a ciência da informação tem caminhado para a consolidação de perspectivas calcadas em aspectos do chamado paradigma social. Isso evidencia uma tendência, que é também um olhar mais atento à complexidade dos fenômenos, ao inter-relacionamento de seus elementos e dimensões, bem como aos novos aspectos das realidades empíricas que demandam novos modelos explicativos.

\section{REFERÊNCIAS}

ALMEIDA, M. A.; DAMIAN, I. P. M. Humanidades digitais: um campo praxiológico para mediações e políticas culturais? In: ENCONTRO NACIONAL DE PESQUISA EM CIÊNCIA DA INFORMAÇÃO, 16., 2015, João Pessoa. Anais... João Pessoa: Associação Nacional de Pesquisa e Pós-Graduação em Ciência da Informação, 2015. Disponível em: <http://www.ufpb.br/evento/lti/ocs/index.php/enancib2015/enancib2015/paper/vie w/2999/1046>. Acesso em: 01 set. 2017.

ALVES, C. A.; DUARTE, E. N. Cultura e informação: uma interface complexa e definidora na vida das organizações. Revista Brasileira de Biblioteconomia e Documentação, São Paulo, v. 10, n. 1, p. 2-20, jul. 2014. Disponível em: <https://rbbd.febab.org.br/rbbd/article/view/275>. Acesso em: 01 set. 2017.

\section{ARAÚJO, C. A. Á. Arquivologia, biblioteconomia, museologia e ciência da} informação: o diálogo possível. Brasília: Briquet de Lemos, 2014.

BATES, M. The information professions: knowledge, memory, heritage. In: ASSOCIATION FOR LIBRARY AND INFORMATION SCIENCE EDUCATION CONFERENCE, 1., 2012.

Anais... Dallas: Association for Library and Information Science Education, 2012.

BRAMAN, S. The emergent global information policy regime. In: BRAMAN, S. (Ed.). The emergent global information policy regime. Houndsmills: Palgrave Macmillan, 2004. p. 12-37.

BURKE, P. Uma história social do conhecimento II: da Enciclopédia à Wikipédia. Rio de Janeiro: Zahar, 2012.

CAPURRO, R. Desafíos téoricos y prácticos de la ética intercultural de la información. In: FREIRE, G. H. A. (Org.). Ética da informação: conceitos, abordagens, aplicações. João Pessoa: Ideia, 2010. p. 11-51. Disponível em: <http://ru.ffyl.unam.mx/bitstream/handle/10391/1328/teaching\%20information\%20 ethics.pdf;jsessionid=274E938415F797ADF4E6BAF74E94A469? sequence $=1>$. Acesso em: 01 set. 2017. 
CAPURRO, R. Epistemologia e ciência da informação. In: ENCONTRO NACIONAL DE PESQUISA EM CIÊNCIA DA INFORMAÇÃO, 5., 2003, Belo Horizonte. Anais... Belo Horizonte: Associação Nacional de Pesquisa e Pós-Graduação em Ciência da Informação, 2003.

CAPURRO, R.; HJORLAND, B. O conceito de informação. Perspectivas em Ciência da Informação, v. 12, n. 1, p. 148-207, jan./abr. 2007.

CATARINO, M. E.; BAPTISTA, A. A. Folksonomias: características das etiquetas na descrição de recursos da web. Informação \& Informação, v. 14, n. esp., p. 46-67, 2009. Disponível em: <http://www.brapci.ufpr.br/brapci/v/a/7944>. Acesso em: 01 set. 2017.

CRONIN, B. The sociological turn in information science. Journal of Information Science, v. 34, n. 4, p. 465-475, 2008. Disponível em: <https://pdfs.semanticscholar.org/0993/0bc077be4751498db22ed7fd74aa33297e30. pdf>. Acesso em: 12 out. 2017.

DAY, R. E. The modern invention of information: discourse, history and power. Carbondale: Southern Illinois University Press, 2001.

FROHMANN, B. O caráter social, material e público da informação. In: FUJITA, M. S.; MARTELETO, R. M.; LARA, M. G. (Org.). A dimensão epistemológica da ciência da informação e suas interfaces técnicas, políticas e institucionais nos processos de produção, acesso e disseminação da informação. São Paulo: Cultura Acadêmica; Marília: Fundepe, 2008. p. 19-34.

FROHMANN, B. Taking information policy beyond information science: applying the actor network theory. In: ANNUAL CONFERENCE OF THE CANADIAN ASSOCIATION FOR INFORMATION SCIENCE, 23., 1995. Anais... Edmonton: Canadian Association for Information Science, 1995.

GARCÍA GUTIÉRREZ, A. Outra memória é possível: estratégias descolonizadoras do arquivo mundial. Petrópolis: Vozes, 2008.

GONZÁLEZ DE GÓMEZ, M. N. A documentação e o neodocumentalismo. In: CRIPPA, G.; MOSTAFA, S. P. (Org.). Ciência da Informação e Documentação. Campinas: Alínea, 2011. p. 23-36.

GONZÁLEZ DE GÓMEZ, M. N. Regime de informação: construção de um conceito. Informação \& Sociedade: Estudos, João Pessoa, v. 22, n. 3, p. 43-60, set./dez. 2012. Disponível em: <http://www.ies.ufpb.br/ojs/index.php/ies/article/view/14376>. Acesso em: 31 ago. 2017.

GOUVEIA, F. C. Altmetria institucional: uma análise dos trabalhos publicados na PLoS ONE pela Fundação Oswaldo Cruz. In: ENCONTRO NACIONAL DE PESQUISA EM CIÊNCIA DA INFORMAÇÃ̃, 17., 2016, Salvador. Anais... Salvador: Associação Nacional de Pesquisa e Pós-Graduação em Ciência da Informação, 2016. Disponível em: 
<http://www.ufpb.br/evento/lti/ocs/index.php/enancib2016/enancib2016/paper/vie w/3720/2539>. Acesso em: 31 ago. 2017.

GOUVEIA, F. C. Altmetria: métricas de produção científica para além das citações. Liinc em Revista, v. 9, n. 1, p. 214-227, maio 2013. Disponível em:

<http://revista.ibict.br/liinc/article/view/3434/3004>. Acesso em: 31 ago. 2017.

GRACIOSO, L. S. Parâmetros teóricos para elaboração de instrumentos pragmáticos de representação e organização da informação na Web: considerações preliminares sobre uma possível proposta metodológica. InCID: Revista de Ciência da Informação e Documentação, Ribeirão Preto, v. 1, n. 1, p. 138-158, jul. 2010. Disponível em: <https://www.revistas.usp.br/incid/article/view/42310>. Acesso em: 01 set. 2017.

GUEDES, R. M.; MOURA, M. A.; DIAS, E. J. W. Indexação Social e Pensamento Dialógico: reflexões teóricas. Informação \& Informação, v. 16, n. 3, p. 40-59, dez. 2011. Disponível em: <http://www.uel.br/revistas/uel/index.php/informacao/article/view/10477>. Acesso em: 01 set. 2017.

GUIMARÃES, J. A. C. Análise de domínio como perspectiva metodológica em organização da informação. Ciência da Informação, v. 43, n. 1, jun. 2015. Disponível em:

<http://revista.ibict.br/ciinf/article/view/1415/1593>. Acesso em: 31 ago. 2017.

HALBWACHS, M. A memória coletiva. São Paulo: Centauro, 2003.

HJORLAND, B.; ALBRECHTSEN, H. Toward a new horizon in information science: domain-analysis. Journal of the American Society for Information Science, v. 46, n. 6, p. 400-425, 1995.

IULIANELLI, J. A. S. Contribuições habermasianas para uma ética intercultural da informação: aproximações. LOGEION: Filosofia da informação, Rio de Janeiro, v. 3 n. 1, p. 29-41, set. 2016/mar. 2017. Disponível em:

<http://revista.ibict.br/fiinf/article/view/3006>. Acesso em: 01 set. 2017.

MACHADO, K. C.; VIANNA, W. B. Curadoria digital e ciência da informação: correlações conceituais relevantes para apropriação da informação. In: ENCONTRO NACIONAL DE PESQUISA EM CIÊNCIA DA INFORMAÇÃO, 17., 2016, Salvador. Anais... Salvador: Associação Nacional de Pesquisa e Pós-Graduação em Ciência da Informação, 2016. Disponível em:

<http://www.ufpb.br/evento/lti/ocs/index.php/enancib2016/enancib2016/paper/vie w/3867/2452>. Acesso em: 01 set. 2017.

MARCHAND, D. A.; KETTINGER, W.; ROLLINS, J. D. Information orientation: the link to business performance. Oxford: Oxford University Press, 2001.

MATTELART, A. História da sociedade da informação. São Paulo: Loyola, 2002.

McKENZIE, P. A model of information practices in accounts of everyday-life information seeking. Journal of Documentation, v. 59. n. 1, p. 19-40, 2003. Disponível em: <http://publish.uwo.ca/ pmckenzi/McKenzie_J.Doc_2003.pdf>. Acesso em: 01 set. 2017. 
MELO, W. L.; PRESSER, N. H.; SANTOS, R. N. M. Cultura organizacional e ciência da informação: a percepção da ocorrência da temática na Base de Dados Referenciais de Artigos de Periódicos em Ciência da Informação (BRAPCI). In: ENCONTRO NACIONAL DE PESQUISA EM CIÊNCIA DA INFORMAÇÃO, 14., 2013, Florianópolis. Anais...

Florianópolis: Associação Nacional de Pesquisa e Pós-Graduação em Ciência da Informação, 2013. Disponível em:

<http://enancib.ibict.br/index.php/enancib/xivenancib/paper/view/4006/3129>. Acesso em: 31 ago. 2017.

MURGUIA, E. I. (Org.). Memória: um lugar de diálogo para arquivos, bibliotecas e museus. São Carlos: Compacta, 2010.

NORA, P. Entre memória e história: a problemática dos lugares. Projeto História, n. 10, p. 7-28, dez. 1993.

PIMENTA, R. M. Os objetos técnicos e seus papéis no horizonte das Humanidades Digitais: um caso para a Ciência da Informação. Revista Conhecimento em Ação, Rio de Janeiro, v. 1, n. 2, p. 20-33, jul./dez. 2016. Disponível em:

<https://revistas.ufrj.br/index.php/rca/article/view/20>. Acesso em: 01 set. 2017.

PRIEM, J.; GROTH, P.; TARABORELLI, D. Altmetrics: a manifesto. Disponível em: <http://altmetrics.org/manifesto>. Acesso em: 31 ago. 2017.

SAVOLAINEN, R. Everyday life information seeking: approaching information seeing in the context of way of life. Library and Information Science Research, n. 17, p. 259-294, 1995.

SAYÃO, L. F.; SALES, L. F. Curadoria digital: um novo patamar para preservação de dados digitais de pesquisa. Informação \& Sociedade: Estudos, João Pessoa, v. 22, n. 3, p. 179191, set./dez. 2012. Disponível em:

<http://www.ies.ufpb.br/ojs/index.php/ies/article/view/12224>. Acesso em: 01 set. 2017.

SIEBRA, S. A. et al. Curadoria digital: além da questão da preservação digital. In: ENCONTRO NACIONAL DE PESQUISA EM CIÊNCIA DA INFORMAÇÃO, 14., 2013, Florianópolis. Anais... Florianópolis: Associação Nacional de Pesquisa e Pós-Graduação em Ciência da Informação, 2013. Disponível em:

<http://basessibi.c3sl.ufpr.br/brapci/index.php/article/download/40505>. Acesso em: 01 set. 2017.

SILVA, A. M.; RIBEIRO, F. Das “ciências" documentais à ciência da informação: ensaio epistemológico para um novo modelo curricular. Porto: Afrontamento, 2002.

SILVA, J. L. C. Informação e ética: entre o universalismo e relativismo e/ou da ética alteritária da informação. In: ENCONTRO NACIONAL DE PESQUISA EM CIÊNCIA DA INFORMAÇÃO, 16., 2015, João Pessoa. Anais... João Pessoa: Associação Nacional de Pesquisa e Pós-Graduação em Ciência da Informação, 2015. Disponível em: 
<http://www.ufpb.br/evento/lti/ocs/index.php/enancib2015/enancib2015/paper/vie wFile/2916/988>. Acesso em: 01 set. 2017.

SOUZA, I. V. P. Altmetria: métricas alternativas do impacto da comunicação científica. 2014. 104 f. Dissertação (Mestrado) - Programa de Pós-Graduação em Ciência da Informação, Universidade Federal Fluminense, Niterói, 2014. Disponível em: <http://www.repositorio.uff.br/jspui/handle/1/2811>. Acesso em: 04 nov. 2017.

TENNIS, J. T. Com o que uma análise de domínio se parece no tocante à sua forma, função e gênero? Brazilian Journal of Information Science, Marília, v. 6, n. 1, p. 3-15, jan./jun. 2012. Disponível em:

<http://basessibi.c3sl.ufpr.br/brapci/index.php/article/view/0000013187/308a95f66 80faf537e3f731b4100f11e>. Acesso em: 31 ago. 2017.

TUOMINEN, K.; TALJA, S.; SAVOLAINEN, R. Discourse, cognition and reality: toward a social constructionist metatheory for library and information science. In: BRUCE, H. et al. (Org.). Emerging frameworks and methods. Greenwood Village: Libraries Unlimited, 2002. p. 271-283.

VIVARELLI, M. Il racconto dell'architettura: Biblioteche, musei, archivi nella recente esperienza francese in un dossier del "Bulletin des bibliothèques de France".

Biblioteche Oggi, v. 33, p. 55-63, abr. 2015.

WOIDA, L. M.; VALENTIM, M. L. P. Cultura organizacional/cultura informacional: a base do processo de inteligência competitiva organizacional. In: VALENTIM, M.L.P. (Org.).

Informação, conhecimento e inteligência organizacional. Marília: Fundepe, 2006. p. $25-44$.

\section{SOBRE O AUTOR}

Carlos Alberto Ávila Araújo

Professor associado da Escola de Ciência da Informação da UFMG. Pós-doutor pela Universidade do Porto.

E-mail: casalavila@yahoo.com.br

Recebido em: 01/09/2017; Revisado em: 04/11/2017; Aceito em: 16/11/2017.

\section{Como citar este artigo}

ARAÚJO, Carlos Alberto Ávila. Teorias e tendências contemporâneas da ciência da informação.

Informação em Pauta, Fortaleza, v. 2, n. 2, p. 9-34, jul./dez. 2017. 